\title{
Analisis Reliabilitas dan Availabilitas pada Mesin Produksi Lampu Pijar Sistem Seri Menggunakan Pendekatan Analisis Markov di PT. Sinar Angkasa Rungkut
}

\author{
Ramadhani Etika Wulandari, Diaz Fitra Aksioma, dan Haryono \\ Departemen Statistika, Fakultas Matematika, Komputasi, dan Sains Data \\ Institut Teknologi Sepuluh Nopember (ITS) \\ e-mail: haryono@statistika.its.ac.id
}

\begin{abstract}
Abstrak - Penambahan daya listrik oleh negara akan secara langsung mengerek permintaan lampu. PT. Sinar Angkasa Rungkut merupakan produsen lampu merek Chiyoda dengan lini produksi yang terdiri dari lampu pijar, lampu neon dan lampu LED. Setiap unit produksi lampu pijar terdiri dari lima mesin yaitu mesin Flare, mesin Stem, mesin Mounting, mesin Sealex, dan mesin Basing. Unit 22 seringkali belum mampu mencapai target yang ditetapkan dimana hal ini disebabkan oleh sering terjadinya kerusakan mesin produksi pada unit 22 yang menunjukkan bahwa belum optimalnya perawatan mesin. Reliabilitas adalah peluang suatu mesin untuk bekerja dengan sebagaimana mestinya pada waktu dan kondisi tertentu. Analisis reliabilitas adalah metode yang digunakan untuk menghitung peluang mesin atau komponen beroperasi dengan baik. Availabilitas adalah peluang suatu sistem beroperasi pada suatu waktu atau dalam selang waktu tertentu dan mengandung kondisi perbaikan. Availabilitas dapat digunakan untuk menilai keberhasilan atau efektifitas dari kegiatan perawatan yang telah dilakukan. Evaluasi untuk kondisi sistem produksi unit 22 dilakukan menggunakan analisis availabilitas dan reliabilitas menggunakan pendekatan analisis Markov dan pendekatan diferensial sebab kondisi subsistem saling dependen. Hasil penelitian menunjukkan agar performance sistem meningkat, subsistem Sealex harus diberi prioritas utama dalam hal maintenance. Hal itu disebabkan karena perubahan laju kerusakan subsistem Sealex memberikan perubahan yang signifikan terhadap availabilitas dan reliabilitas sistem.
\end{abstract}

Kata Kunci-Analisis Availabilitas, Analisis Markov, Analisis Reliabilitas, Maintenance.

\section{PENDAHULUAN}

$\mathrm{P}$ T. Sinar Angkasa Rungkut merupakan produsen lampu merek Chiyoda yang telah menjadi salah satu produsen lampu terkemuka di Indonesia dengan lini produksi yang terdiri dari lampu pijar, lampu neon dan lampu LED. Mesin dan peralatan yang digunakan dalam memproduksi lampu didatangkan dari negara-negara industri maju seperti Jepang dan Taiwan. PT. Sinar Angkasa Rungkut memiliki beberapa unit produksi dalam memproduksi lampu pijar. Setiap unit terdiri dari lima mesin yaitu mesin Flare, mesin Stem, mesin Mounting, Mesin Sealex, dan Mesin Basing. Salah satu unit produksi yang melakukan running paling banyak yaitu unit 22 dimana unit tersebut memproduksi lampu pijar dekorasi tipe C 35, G 45, dan G 40. Unit 22 seringkali belum mampu mencapai target yang ditetapkan. Hal ini disebabkan oleh sering terjadinya kerusakan mesin produksi pada unit 22 yang menunjukkan bahwa belum optimalnya perawatan mesin dan dapat dinyatakan availabilitas serta keandalan mesin masih rendah. Reliabilitas merupakan cabang dari ilmu statistika yang meneliti mengenai keandalan suatu mesin. Reliabilitas adalah peluang suatu mesin untuk bekerja dengan sebagaimana mestinya pada waktu dan kondisi tertentu. Availabilitas adalah peluang suatu sistem beroperasi pada suatu waktu atau dalam selang waktu tertentu dan mengandung kondisi perbaikan. Availabilitas juga dapat digunakan untuk menilai keberhasilan dari kegiatan perawatan yang telah dilakukan.

Lampu pijar adalah salah satu jenis lampu yang sudah tidak asing digunakan oleh masyarakat. Meskipun pemerintah telah menghimbau masyarakat untuk menggunakan lampu hemat energi, namun dalam kenyataannya masih ada masyarakat yang memilih menggunakan lampu pijar sebagai penerangan karena harganya yang murah dan mudah didapat. Dalam memanfaatkan lampu sebagai pemercantik ruangan, masyarakat juga lebih memilih lampu pijar dekorasi yang memiliki bentuk menarik dan cukup bervariasi. Penambahan daya listrik oleh negara akan secara langsung mengerek permintaan lampu [1]. Kebutuhan total lampu tahun 2017 adalah sekitar 350 juta unit dan tahun 2018 diprediksi di sekitar 400 juta unit.

Maintenance merupakan suatu kegiatan yang dilakukan secara berulang-ulang dengan tujuan agar peralatan selalu memiliki kondisi yang sama seperti keadaan semula. Jika pemeliharaan tidak terjadwal dan diatur secara baik, maka pemeliharaan dapat menimbulkan biaya dan kerugian yang besar bagi perusahaan [2]. Pada penelitian ini peneliti melakukan analisis menggunakan pendekatan analisis Markov dan pendekatan diferensial karena sistem produksi pada unit 22 PT. Sinar Angkasa Rungkut memiliki kondisi dependen. Analisis availabilitas mesin pernah diterapkan oleh Gupta dan kawan-kawan pada proses pembuatan butter-oil dan oleh Astarini di sebuah pabrik semen.

Tujuan dari penelitian ini adalah mengevaluasi kondisi sitem menggunakan analisis availabilitas, reliabilitas, dan dengan menentukan probabilitasa sistem berada pada suau state proses produksi di PT. Sinar Angkasa Rungkut, dan mengidentifikasi subsistem yang memberikan pengauh besar terhadap kondisi sistem. 


\section{TINJAUAN PUSTAKA}

A. $\quad$ Proses Produksi Lampu Pijar Dekorasi Unit 22 di PT. Sinar Angkasa Rungkut

Produksi lampu pijar dilakukan menggunakan lima mesin utama yakni mesin Flare, Stem, Mouting, Sealex, dan Basing.Tahap pertama dalam pembuatan lampu pijar berada pada mesin Flare. Pada tahap ini, tube flare dimasukkan pada mesin Flare lalu dilakukan pemotongan. Hasil dari proses ini disebut flare.

Tahap selanjutnya dilakukan pada mesin Stem. Proses stem merupakan proses penggabungan antara flare, exhaust tube dan lead-in wire.

Mounting merupakan mesin produksi tahap ketiga. Proses ini diawali dengan memasukkan stem ke dalam head berupa konveyor yang menuju ke head mounting. Selanjutnya lead-in wire diluruskan ke samping dan ujungnya ditekuk sebagai tempat penjepit filament. Setelah filament dipasangkan pada kaitan tersebut, kemudian kaitan tersebut ditutup. Akhir dari proses mounting ini adalah proses perapatan lead-in wire seperti posisi semula.

Tahap keempat berada pada mesin Sealex yangmerupakan gabungan antara mesin sealing dan mesin exhausting. Pada proses sealing lakukan pemanasan untuk menggabungkan hasil mounting dengan glass bulb. Kemudian hasil sealing masuk ke mesin exhausting. Pada bagian exhausting ini, dilakukan proses pemvakumkan dengan cara menghisap udara yang berada dalam bulb dengan menggunakan $\mathrm{N}_{2}$ melalui bagian tengah exhaust tube yang berlubang.

Tahap terakhir berada pada mesin Basing dimana dilakukan penggabungan base yang dinding dalamnya telah diberi cement dengan bulb lampu setengah jadi.

\section{B. Analisis Markov terhadap Sistem Seri}

Sistem seri merupakan suatu sistem yang terdiri dari beberapa komponen yang dirangkai secara berurutan. Suatu komponen yang dirangka secara seri akan menimbulkan berhentinya operasi ketika terjadi kerusakan pada salah satu komponen dalam rangkaian. Namun ketika terdapat komponen cadangan (komponen pengganti) dalam sistem, kondisi berhentinya operasi dapat dihindari.

Reliabilitas adalah peluang suatu mesin untuk bekerja dengan sebagaimana mestinya pada waktu dan kondisi tertentu. Availabilitas adalah peluang suatu sistem beroperasi pada suatu waktu atau dalam selang waktu tertentu dan mengandung kondisi perbaikan. Availabilitas dapat digunakan untuk menilai keberhasilan atau efektifitas dari kegiatan perawatan yang telah dilakukan Analisis Markov merupakan metode yang dapat digunakan untuk menghitung nilai availabilitas dan reliabilitas dari kondisi tersebut. Apabila antar subsistem saling independen, reliabilitas sistem seri dapat dihitung menggunakan rumus.

$$
R_{s}=R_{1} \times R_{2} \times \cdots \times R_{n}=\prod_{i}^{n} R_{i}
$$

$R_{i}$ merupakan reliabilitas subsistem ke-i dengan $\mathrm{i}=1,2, \ldots, \mathrm{n}$. Namun, ketika subsistem saling dependen dan subsisem yang rusak dapat diperbaiki agar berfungsi kembali, maka digunakan pendekatan Persamaan diferensial yang didasarkan pada diagram transisi markov. Rata-rata waktu antar kerusakan (MTTF) dan rata-rata waktu perbaikan (MTTR) untuk data memiliki distribusi Eksponensial dijabarkan sebagai berikut [3].

$$
\operatorname{MTTF}_{s}=\frac{1}{\alpha_{s}}=\frac{1}{\sum_{i=1}^{n} \alpha_{i}} \text { dan MTTRs }=\frac{1}{\beta}=\frac{1}{\sum_{i=1}^{n} \beta_{i}}
$$

$\alpha_{i}$ merupaka laju kerusakan subsistem sedangkan $\beta$ merupaka laju perbaikan subsistem dapat diperoleh dengan Persamaan (3) dan n merupakan banyaknya subsistem.

$$
\alpha_{i}=\frac{m}{\sum_{i=1}^{m} x_{i}} \operatorname{dan} \beta_{i}=\frac{m}{\sum_{i=1}^{m} y_{i}},
$$

di mana $x$ adalah data waktu kerusaka ke-i dan $y$ adala data lama perbaikan dari kerusakan ke-1 (l=1,2,..,m), dimana $m$ merupakan banyaknya data waktu kerusakan dan lama perbaikan subsistem.Diagram transisi Markov secara umum digambarkan pada Gambar 1.

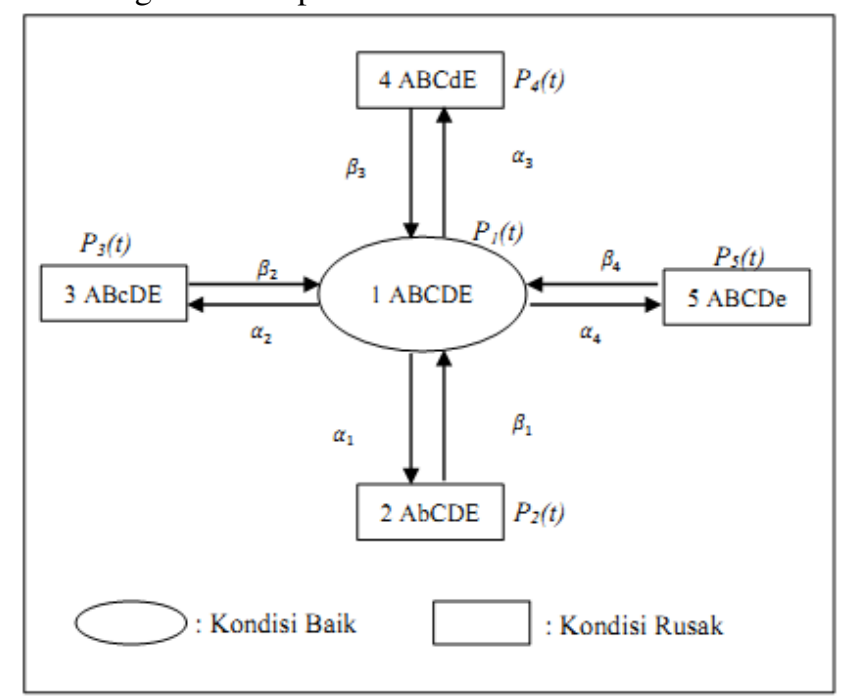

Gambar 1. Diagaram Transisi Proses Produksi Lampu Pijar Berikut adalah pengertian dari simbol-simbol yang digunakan dalam diagram transisi.

a. A,B, C, D, dan E merupakan simbol yang menyatakkan subsistem dari proses produksi dalam kondisi baik.

b. a, b, c, d, dan e merupakan simbol yang menyatakan subsistem dari proses produksi dalam kondisi rusak.

c. $\quad \alpha_{i}$ dengan $\mathrm{i}=1,2,3,4$, dan 5 merupakan simbol yang menyatakan laju kerusakan subsistem A,B,C,D, dan E

d. $\quad \beta_{i}$ dengan $\mathrm{i}=1,2,3,4$, dan 5 merupakan simbol yang menyatakan laju perbaikan subsistem A,B,C,D, dan E e.

dengan $\mathrm{j}=1,2,3,4$, dan 5 merupakan simbol yang menyatakan probabilitas sistem berada pada state ke-j di waktu ke-t.

Berdasarkan Gambar 1, diperoleh Persamaan diferensial pada state1 hingga state 5 sebagai berikut.

$$
\begin{aligned}
P_{1}^{\prime}= & {\left[-\alpha_{1}-\alpha_{2} \cdots-\alpha_{4}\right] P_{1}(t)+P_{2}(t) \beta_{1}+P_{3}(t) \beta_{2} } \\
& +\cdots+P_{5}(t) \beta_{4} \\
P_{2}^{\prime}= & \alpha_{1} P_{1}(t)+P_{2}(t) \beta_{1} \\
P_{3}^{\prime}= & \alpha_{2} P_{1}(t)+P_{3}(t) \beta_{2} \\
P_{4}^{\prime}= & \alpha_{3} P_{1}(t)+P_{4}(t) \beta_{3} \\
P_{5}^{\prime}= & \alpha_{4} P_{1}(t)+P_{5}(t) \beta_{4}
\end{aligned}
$$




$$
P_{1}(t)+P_{2}(t)+\cdots+P_{5}(t)=1
$$

Persamaan (4) hingga (5) dengan kondisi awal $\mathrm{t}=0$ adalah $P_{j}(0)=1$ untuk $j=1$ dan $P_{j}(0)=0$ untuk $j$ lainnya. Persamaan diferensial tersebut dapat diselesaikan dengan metode Runge-Kutta. Availabilitas sistem jangka panjang atau pada saat steady state dengan mengikuti aturan. Availabilitas sistem jangka panjang atau pada saat steady state dengan mengikuti aturan

$$
\frac{d P_{j}(t)}{d t}=0 \text { dengan } t \rightarrow \infty \text {. }
$$

Mengacu pada persaan diferensial pada Persamaan (4) hingga Persamaan (5), peluang dari setiap state pada saat steady state, $\quad P_{i}(t \rightarrow \infty)$ disimbolkan dengan $P_{i}$ adalah sebagai berikut.

$$
\begin{gathered}
P_{2}=\frac{\alpha_{1}}{\beta_{1}} P_{1}, \\
P_{3}=\frac{\alpha_{2}}{\beta_{2}} P_{1}, \\
P_{4}=\frac{\alpha_{3}}{\beta_{3}} P_{1}, \\
P_{5}=\frac{\alpha_{4}}{\beta_{4}} P_{1},
\end{gathered}
$$

Oleh karena

$$
P_{1}\left(1+\frac{\alpha_{1}}{\beta_{1}}+\frac{\alpha_{2}}{\beta_{2}}+\frac{\alpha_{3}}{\beta_{3}}+\frac{\alpha_{4}}{\beta_{4}}\right)=1,
$$

maka availabilitas jangka panjang dapat dihitung dengan cara

$$
A(\infty)=P_{1}=\frac{1}{\left(1+\frac{\alpha_{1}}{\beta_{1}}+\frac{\alpha_{2}}{\beta_{2}}+\frac{\alpha_{3}}{\beta_{3}}+\frac{\alpha_{4}}{\beta_{4}}\right)} .
$$

Reliabilitas sistem dihitung menggunakan Persamaan yang dinyatakan sebagai berikut [3].

$$
R(t)=P_{1}(t) \text {. }
$$

\section{Metode Runge-Kutta}

Metode Runge-Kutta mencapai keakuratan dari suatu pendekata Taylor tanpa memerlukan turunan-turunan tingkat tinggi. Bantuk umum metode Runge-Kutta dijabarkan sebagai berikut.

dan,

$$
y_{0}=\alpha,
$$

$$
y_{i+1}=y_{1}+h F\left(x_{i}, y_{i}\right),
$$

dengan $\mathrm{i}=0,1,2$,.. fungsi $F$ disebut sebagai fungsi kenaikan yang dapat ditulis dalam Persamaan berikut.

$$
F=\alpha_{1} k_{1}+\alpha_{2} k_{2}+\ldots+\alpha_{o} k_{o},
$$

Dimana $o$ merupakan orde dari metode Runge-Kutta, $k_{i}$ adalah konstanta yang dijabarkan sebagai berikut.

$$
k_{i}=f\left(\begin{array}{c}
x_{i}+p_{m-1} h, y_{i}+q_{o-1,1} k_{1} h+q_{o-1,2} k_{2} h \\
+\ldots+q_{o-1,0-1} k_{o-1} h
\end{array}\right)
$$

Nilai-nilai $\alpha_{i}, p_{i}$ dan $q_{i j}$ untuk suatu orde $o$ dinyatakan dengan cara menyamkan Persamaan dengan ekspansi deret
Taylor orde $o$ [4]. Berikut merupakan bentuk Persamaan untuk metode Runge-Kutta orde 4 [5].

$$
y_{r+1}=y_{r}+\frac{1}{6}\left(k_{1}+2 k_{2}+2 k_{3}+k_{4}\right),
$$

dengan $k_{1}$ diperoleh dari Persamaan (2.20) dan $k_{2}, k_{3}$, dan, $k_{4}$

$$
\begin{gathered}
k_{2}=h f\left(x_{r}+\frac{1}{2} h, y_{r}+\frac{1}{2} k_{1}\right), \\
k_{3}=h f\left(x_{r}+\frac{1}{2} h, y_{r}+\frac{1}{2} k_{2}\right), \\
k_{4}=h f\left(x_{r}+h, y_{r}+k_{3}\right),
\end{gathered}
$$

\section{Maintenance}

Maintenance atau perawatan merupakan segala kegiatan yang dilakukan untuk mempertahankan mesin dalam kondisis beroperasi. Terdapat empat jenis sistem pemeliharaan yakni corrective maintenance, preventive maintenance, predictive maintenance, dan repairs maintenance [2].

Corrective maintenance atau pemeliharaan perbaikan merupakan semua kegiatan yang dilakukan untuk mengembalikan kondisi mesin dari status rusak menjadi status beroperasi. Pemeliharaan perbaikan mencakup beberapa kegiatan yang dibagi atas tiga kategori yakni sebagai berikut [6].

\section{Waktu Persiapan}

Waktu persiapan merupakan waktu yang dikeluarkan operator untuk melakukan suatu kegiatan yang terkait dengan perawatan, perbaikan, peralatan, atau perlengkapan.

\section{Waktu Perawatan}

Waktu perawatan merupakan waktu yang dikeluarkan unruk melakukan kegiata perawatan, perbaikan, mengambilan alat, serta mengecek alat atau perlengkapan.

3. Waktu Menunggu

Waktu menggu adalah waktu yang dikeluarkan untuk menunggu suku cadang ketika kegiatan perawatan atau perbaikan sedang dilakukan.

Preventive maintenance merupakan pemeliharaan terjadwal yang dilakukan secara periodik berbentuk inspeksi dan perbaikan, pergantian, pembersihan, pelumasan, serta penyesuaian. Predictive maintenance merupakan sebuah cara perawatan yang menggunakan berbagai alat ukur spesifik untuk menilai sebuah perubahan pada suatu benda atau keadaan. Repairs maintenance merupakan suatu metode yang hanya dilakukan ketika dibutuhkan atau terjadi kerusakan. Perawatan jenis ini lebih sering diterapkan pada kmponen-komponen yang tidak tergoong komponen kritis atau komponen utama [2].

\section{METODOLOGI PENELITIAN}

\section{A. Sumber data}

Data yang digunakan dalam penelitian adalah data sekunder yang diperoleh dari PT. Sinar Angkasa Rungkut. Data meliputi data usia pakai dan data lama waktu perbaikan yang terjadi di mesin Flare, mesin Steam, mesin Mounting, Mesin Sealex, dan mesin Basing. Data yang digunakan dimulai dari bulan Januari 2016 hingga bulan Desember 2017. Pengambilan data dilakukan oleh operator yang bertugas di masing-masing area produksi sebagai bahan evaluasi performance mesin produksi di PT. Sinar Angkasa Rungkut. 


\section{B. $\quad$ Variabel Penelitian}

Variabel yang digunakan dalam penelitian ini adalah usia pakai mesin dan lama waktu perbaikan seperti yang tertera pada Tabel 3.1. Usia pakai dihitung mulai dari mesin mulai beroperasi hingga berhenti beroperasi karena mati, mendapatkan perbaikan, dan pemeliharaan. Lama waktu perbaikan dihitung mulai dari mesin mulai mendapat perbaikan sampai dengan selesai perbaikan.

Tabel 1.

Variabel yang Digunakan dalam Penelitian

\begin{tabular}{|c|c|c|c|}
\hline No & Variabel Penelitian (jam) & No & Variabel Penelitian (jam) \\
\hline 1 & Usia pakai mesin Flare & 6 & $\begin{array}{l}\text { Lama waktu perbaikan } \\
\text { mesin Flare }\end{array}$ \\
\hline 2 & Usia pakai mesin Steam & 7 & $\begin{array}{l}\text { Lama waktu perbaikan } \\
\text { mesin Steam }\end{array}$ \\
\hline 3 & $\begin{array}{l}\text { Usia pakai mesin } \\
\text { Mounting }\end{array}$ & 8 & $\begin{array}{l}\text { Lama waktu perbaikan } \\
\text { mesin Mounting }\end{array}$ \\
\hline 4 & Usia pakai mesin Sealex & 9 & $\begin{array}{l}\text { Lama waktu perbaikan } \\
\text { mesin Sealex }\end{array}$ \\
\hline 5 & Usia pakai mesin Basing & 10 & $\begin{array}{l}\text { Lama waktu perbaikan } \\
\text { mesin Basing }\end{array}$ \\
\hline
\end{tabular}

\section{Langkah Analisis Data}

Langkah analisis yang dilakukan untuk mencapai tujuan penelitian adalah sebagai berikut.

i. Menghitung laju kerusakan dan laju perbaikan masingmasing subsistem menggunakan Persamaan (3)

ii. Identifikasi state dari unit 22 di Pt. Sinar Angkasa Rungkut

iii. Membentuk diagram transisisi berpacu pada Gambar 1 .

iv. Membuat Persamaan diferensial berdasarkan diagram menggunakan Persamaan(4)

v. Menghitung nilai probabilitas sistem berada pada state ke-j untuk kondisi steady state dan transient state menggunakan Persamaan (6)

vi. Menyelesaikan Persamaan diferensial dengan metode Runge-Kutta orde 4 untuk menentukan probabilitas sistem pada kondisi transient state atau kndisi dipengaruhi oleh waktu menggunakan Persamaan (10) dan (11)

vii. Menghitung efek perubahan laju kerusakan atau laju perbaikan terhadap availabilitas dan reliabilitas sistem menggunakan Persamaan (7) dan (8)

viii. Menarik Kesimpulan

\section{ANALISIS DAN PEMBAHASAN}

A. Pemodelan Markov Sistem Produksi di PT. Sinar Angkasa Rungkut

Pembentukan model Markov didasarkan pada kondisi sistem produksi di PT. Sinar Angkasa Rungkut. Data penunjang yang dibutuhkan dalam pemodelan adalah laju kerusakan dan laju perbaikan dari masing-masing subsistem yang diasumsikan memiliki distribusi Eksponensial dan dihitung berdasarkan Persamaan (2). Berikut disajikan perhitungan laju kerusakan dan laju perbaikan untuk masing-masing subsistem.

Tabel 2.

Laju Kerusakan dan Laju Perbaikan Subsistem

\begin{tabular}{ccc}
\hline \hline Subsistem & $\begin{array}{c}\text { Laju } \\
\text { Kerusakan }\end{array}$ & Laju Perbaikan \\
\hline Flare & - & - \\
Stem & 0,004740 & 2,6250 \\
Mounting & 0,005719 & 1,8461 \\
Sealex & 0,011028 & 2,3158 \\
Basing & 0,000606 & 1,0286 \\
\hline \hline
\end{tabular}

Berdasarkan Tabel 2, terlihat bahwa subsistem Flare tidak pernah mengalami kerusakan dalam kurun waktu yang diambil pada penelitian ini. Subsistem Sealex merupakan subsistem yang paling sering mengalami kerusakan jika dibandingkan dengan subsistem lainnya. Sebab, laju kerusakan subsistem Sealex paling tinggi yaitu 0,0110 kerusakan/jam atau subsistem akan mengalami kerusakan setelah dioperasikan selama 91 jam atau selama 11 hari. Namun, kondisi tersebut berbanding terbalik dengan subsistem Basing yang memiliki laju kerusakan paling sebesar 0,000606 kerusakan/jam atau subsistem mengalami kerusakan setalah dioperasikan selama 1653 jam atau selama 206 hari.

Setelah diketahui laju kerusakan dan laju perbaikan masing-masing subsistem, maka dibentuk diagram transisi markov yang ditampilan pada Gambar 1. Pada Gambar 2 disajikan diagram transisi Markov untuk sistem produks di PT. Sinar Angkasa Rungkut.

Gambar 2 menjelaskan kondisi yang mungkin terjadi pada produksi di PT. Sinar Angkasa Rungkut. State 1 menunjukkan kondisi seluruh subsistem beroperasi dengan baik. State 2 menunukkan kondisi subsistem Stem rusak sedangkan subsistem lainnya beroperasi dengan baik. State 3 menunjukkan kondisi subsistem Mounting rusak sedangkan subsistem lainnya beroperasi dengan baik. State 4 menunjukkan kondisi subsistem Sealex rusak sedangkan subsistem lainnya beroperasi dengan baik. State 5 menunjukkan kondisi subsistem Basing rusak sedangkan subsistem lainnya beroperasi dengan baik.

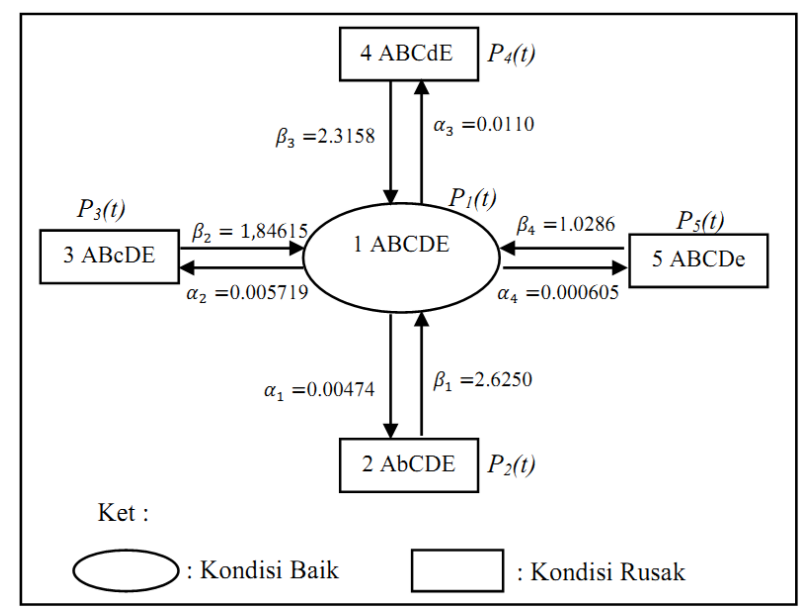

Gambar 2. Diagram Transisi Proses Produksi di PT. Sinar Angkasa Rungkut.

Mengacu pada diagram transisi pada Gambar 2 serta laju kerusakan dan laju perbaikan pada Tabel 2, dibentuk Persamaan diferensial untuk setiap stateyang disesuaikan dengan formula pada Persamaan (4) sebagai berikut.

$$
\begin{aligned}
& P_{1}^{\prime}=-0,022065 P_{1}(t)+2,6250 P_{2}(t)+1,84615 P_{3}(t) \\
& \quad+2,3158 P_{4}(t)+1,0286 P_{5}(t) \\
& P_{2}^{\prime}=0,00474 P_{1}(t)-2,6250 P_{2}(t) \\
& P_{3}^{\prime}=0,005318 P_{1}(t)-1,84615 P_{3}(t) \\
& P_{4}^{\prime}=0,0110 P_{1}(t)-2,3158 P_{4}(t) \\
& P_{4}^{\prime}=0,000605 P_{1}(t)-1,0286 P_{5}(t) \\
& P_{1}(t)+P_{2}(t)+P_{3}(t)+P_{4}(t)+P_{5}(t)=1
\end{aligned}
$$




\section{B. Probabilitas Pada Kondisi Steady state dan} Transient State

Berdasarkan Persamaan diferensial pada uraian sebelumnya, dibentuk Persamaan baru dan dilakukan perhitungan nilai probabilitas setiap state pada kondisi steady state sebagai berikut.

$$
\begin{aligned}
& P_{2}=0,001806 P_{1} \\
& P_{3}=0,003098 P_{1} \\
& P_{3}=0,00475 P_{1} \\
& P_{4}=0,000589 P_{1}
\end{aligned}
$$

Nilai proabilitas sistem berada pada state ke-1 dapat dihitung menggunakan Persamaan (5), sehingga diperoleh nilai 0.989861 . Nilai probabilitas di state ke-1 digunakan untuk menghitung probabilitas di state ke-2, 3, 4, dan 5 dengan mengacu pada Persamaan di uraian sebelumnya. Berikut disajikan ringkasan hasil perhitungan probabilitas sistem berada di state 2, 3, 4 dan 5 pada Tabel 3 .

Tabel 3.

Nilai Probabilitas Setiap State pada Kondisi Steady State

\begin{tabular}{cc}
\hline \hline State ke- & Peluang \\
\hline 1 & 0,989861 \\
2 & 0,001787 \\
3 & 0,003066 \\
4 & 0,004702 \\
5 & 0,000583 \\
\hline \hline
\end{tabular}

Berdasarkan Tabel 3, probabilitas sistem berada pada state-1 adalah sebesar 0,989861 yang berarti besar probabilitas sistem beroperasi dengan baik pada kondisi steady state adala 98\%. Probabilitas subsisem Mounting mengalami kerusakan lebih tinggi dibandingkan dengan yang lainnya karena kerja subsistem Sealex paling berat dan sering terjadi kerusakan mengingat subsistem selaex memiliki dua tugas yaitu sebagai Sealing dan Exhausting dimana sering terjadi kerusakan pada saat transfer bulb atau memindahkan bulb dari sealing menuju ke exhausting.

Probabilitas sistem saat kondisi transient state atau pada kondisi probabilitas dipengaruhi oleh waktu dihitung menggunakan metode numerik Runge-Kutta. Berdasarkan Persamaan diferensial yang diuraikan pada Subbab A, dapat digambarkan kondisi nilai reliabilitas sistem dalam grafik.

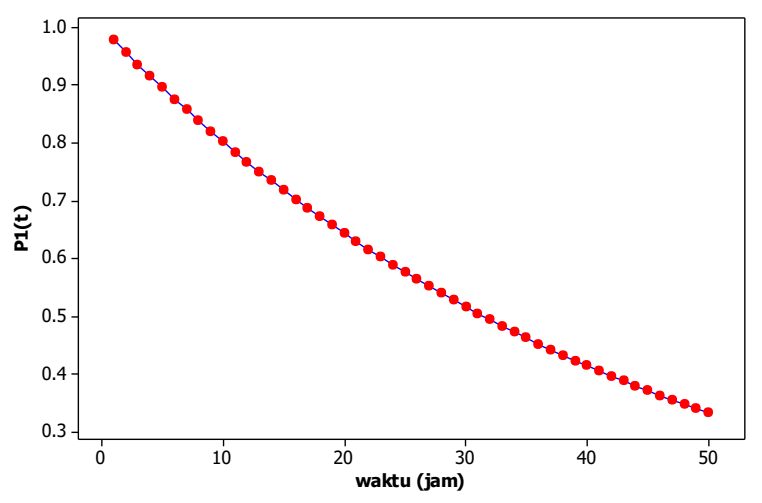

Gambar 3. Nilai Reliabilitas Sistem.

Pada Gambar 3 menunjukkan nilai reliabilitas sistem. Nilai Reliabilitas sistem terlihat menurun dari waktu ke waktu secara drastis. Sehingga, dapat dinyatakan kondisi mesin turun dan maintenance yang dilakukan tidak maksimal.
Gambar 4. menjelaskan bahwa laju kerusakan sistem semakin meningkat dari dari waktu $\mathrm{t}=1$ hingga $\mathrm{t}=50$. Namun di sela peningkatan, laju kerusakan mengalami penurunan saat waktu $t=17$ hingga $t=37$. Kondisi peningkatan laju kerusakan yang terjadi dari waktu ke waktu menunjukkan kondisi sistem tidak reliable atau lemah dan mendapat perawatan yang tidak optimal.

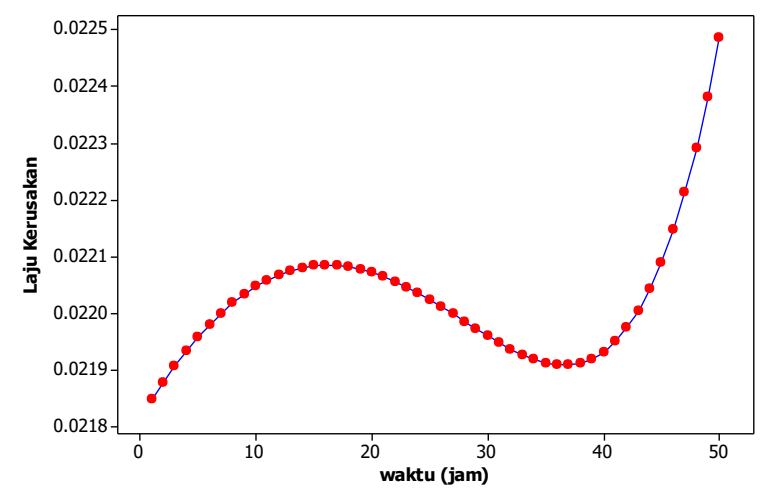

Gambar 4. Grafik Laju Kerusakan Sistem.

C. Efek Perubahan Laju Perbaikan dan Laju Kerusakan terhadap Availabilitas dan Reliabilitas Sistem

Availabilitas sistem dalam jangka panjang dihitung dengan berbagai kondisi laju kerusakan dan laju perbaikan subsistem yang dinilai penting, yaitu subsistem Mounting dan Sealex untuk mengetahui adanya efek perubahan terhadap availabilitas sistem. Laju kerusakan dan laju perbaikan lain bernilai konstan ketika dilakukan perubahan pada subsistem Mounting dan Sealex.

Berdasarkan perhitungan ketika laju kerusakan subsistem Mounting sebesar 0,007 dan laju perbaikan subsistem Mounting sebesar 1,477 maka probabilitas sistem akan beroperasi dengan baik sebesar 98,83\%.Setiap peningkatan 20 persen pada laju kerusakan subsistem Mounting dan penurunan 20 persen pada laju perbaikan Sealex, terjadi penurunan availabilitas sistem hingga 0,77 persen. Ketika laju kerusakan subsistem Sealex sebesar 0,013dan laju perbaikan subsistem Sealex sebesar 1,853 maka probabilitas sistem akan beroperasi dengan baik sebesar $98,75 \%$. Setiap peningkatan 20 persen pada laju kerusakan subsistem Mounting dan penurunan 20 persen pada laju perbaikan Sealex, terjadi penurunan availabilitas sistem hingga 1.17 persen. Penurunan availabilitas tertinggi terjadi ketika kerusakan sering terjadi pada subsistem Sealex. Sehingga subsistem Sealex merupakan subsistem yang memberikan pengaruh terbesar terhadap penurunan availabilitas sistem secara keseluruhan

Perubahan laju kerusakan dilakukan untuk mengetahui subsistem yang memiliki pengaruh penting terhadap reliabilitas sistem. Subsistem yang memberikan penurunan tertinggi pada nilai reliabilitas sistem dinyatakan sebagai subsistem penting

Berdasarkan perhitungan, ketika laju kerusakan subsistem Stem sebesar 0,006 maka probabilitas sistem beroperasi dengan baik setelah digunakan selama 40 jam adalah 39,48\%.Peningkatan laju kerusakan sebesar 20 persen serta penambahan waktu selama 8 jam memberikan efek penurunan reliabilitas sistem mencapai 30,95 persen. Ketika laju kerusakan subsistem Mounting sebesar 0,007 maka probabilitas sistem beroperasi dengan baik setelah digunakan selama 40 jam adalah 39,52\%. Peningkatan laju kerusakan sebesar 20 persen serta penambahan waktu 
selama 8 jam memberikan efek penurunan reliabilitas sistem mencapai 33,49 persen. Ketika laju kerusakan subsistem Mounting sebesar 0,007 maka probabilitas sistem beroperasi dengan baik setelah digunakan selama 40 jam adalah 39,52\%. Peningkatan laju kerusakan sebesar 20 persen serta penambahan waktu selama 8 jam memberikan efek penurunan reliabilitas sistem mencapai 33,49 persen. bahwa ketika laju kerusakan subsistem Basing sebesar 0,00073 maka probabilitas sistem beroperasi dengan baik setelah digunakan selama 40 jam adalah $41,17 \%$. Peningkatan laju kerusakan sebesar 20 persen serta penambahan waktu selama 8 jam memberikan efek penurunan reliabilitas sistem mencapai 20,73 persen.

Hasil analisis perubahan laju kerusakan subsistem menunjukkan bahwa subsistem Sealex yang memberikan efek penurunan tertinggi pada nilai reliabilitas sistem. Oleh karena itu subsistem Sealex harus diprioritaskan dalam maintenance agar reliabilitas sistem meningkat.

\section{KESIMPULAN DAN SARAN}

\section{A. Kesimpulan}

Subsistem Flare tidak pernah mengalami kerusakan dalam kurun waktu penelitian. Subsistem Sealex merupakan subsistem yang paling sering mengalami kerusakan. Ini disebabkan karena laju kerusakan subsistem Sealex paling tinggi yaitu 0,0110 kerusakan/jam atau subsistem akan mengalami kerusakan setelah dioperasikan selama 91 jam atau 11 hari. Subsistem Basing memiliki laju kerusakan yang rendah yaitu sebesar 0,000606 kerusakan/jam atau subsistem mengalami kerusakan setalah dioperasikan selama 1653 jam atau 206 hari.
Pada kondisi steady state, probabilitas sistem berada pada state ke-1 sebesar 0,9898, yangberarti probabilitas sistem beroperasi dengan baik pada kondisi steady state adalah 98\%. Pada kondisi transient state, diketahui terjadi penurunan reliabilitas sistem dari waktu ke waktu yang menunjukkan bahwa ketahanan sistem rendah.

Adanya perubahan laju kerusakan dan laju perbaikan menyebabkan perubahan pada nilai availabilitas dan reliabilitas sistem. Subsistem Sealex dinyatakan sebagai subsistem yang memberikan pengaruh paling besar terhadap nilai availabilitas dan reliabilitas sistem ditinjau dari efek laju kerusakan dan laju perbaikan subsistem.

\section{B. Saran}

Karena penurunan dan kenaikan availabilitas dan reliabilitas sistem yang tinggi dipengaruhi oleh laju kerusakan subsistem Sealex, sebaiknya subsistem Sealex diberi prioritas lebih dalam hal maintenance. Dengan demikian diharapkan laju kerusakan subsistem menurun dan memberikan efek kenaikan pada nilai availabilitas dan reliabilitas sistem.

\section{DAFTAR PUSTAKA}

[1] M. Dinisari, "Ketersediaan Daya Listrik dan Properti Topang Permintaan Lampu 2017," 2017. .

[2] L. Hinggins, R. Mobley, and R. Smith, Maintenance Engineering Handbook. New York: Mc Graw - Hill Inc, 2002.

[3] E. Lewis, Introduction to Reliability Engineering. USA: John Wiley \& Sons, 1995.

[4] R. Munir, Metode Numerik. Bandung: Informatika, 2005.

[5] S. Chapra and R. Canale, Metode Numerik Untuk Teknik, Terjemahan. Jakarta: UI Press, 1991.

[6] P. O'Connor, Practical Reliability Engineering. New York: John Wiley \& Sons, 2004. 